\title{
GLOBAL PARTNERSHIPS IN HUMANITARIAN CRISES: WORLD HEALTH ORGANIZATION'S RESPONSE AND THE SOUTH ASIAN EARTHQUAKE OF OCTOBER 2005
}

\author{
Roberta Ritson \\ World Health Organization \\ and \\ Mona Youssef \\ Webster University, Geneva
}

\section{INTRODUCTION}

The World Health Organization (WHO) is the United Nations specialized agency for health. The goal of the WHO is the "attainment by all peoples of the highest possible level of health." ${ }^{1}$ During humanitarian disasters, WHO responds to the health-related impact of the crisis. In dealing with disasters and crises, WHO seeks to inject and emphasize a public health aspect to humanitarian responses. In order to respond effectively to humanitarian disasters, however, WHO relies on partnerships with other international organizations, nongovernmental organizations (NGOs), governments and the private sector.

WHO recognizes the importance of working in partnership with other key players in health and development when responding to a disaster, whether manmade or natural. This paper outlines not only the way WHO works, but how, in the specific incidence of the 2005 Pakistan earthquake, a humanitarian disaster of major dimensions, partnership operations and collaboration with other institutions and agencies were crucial in tackling this humanitarian crisis.

\section{THE STRUCTURE AND FUNCTIONS OF WHO}

The World Health Organization is the only specialized agency of the United Nations which is mandated to be responsible for global public health. Drawing on the expertise of its medical and health professionals, it performs an important normative role in developing and promoting standards and guidelines to improve public health across the world. In addition to this normative work of trying to raise the level of health and health services in all of its 193 member states, WHO also responds to emergency crises and to health and humanitarian disasters of all kinds, for there is always a health dimension to every humanitarian catastrophe.

The structure of WHO consists of clusters of technical programmes focused on different aspects of public health, such as non-communicable diseases, communicable diseases, health technology and pharmaceuticals, or sustainable development and healthy environments. The department of Governing Bodies 
and External Relations is primarily responsible for communicating the mission of WHO to the outside world and to its partners. Along with other international agencies, NGOs and governments, WHO works with local authorities, civil society, the private sector and major international players in health and development.

The WHO's Health Action in Crisis (HAC) programme is worth noting for its important contribution to assisting victims during and after humanitarian crises. The mission of the HAC programme is to reduce avoidable loss of life, burden of disease and disability in crisis-prone and crisis-affected countries. The HAC programme played a leadership role amongst many other humanitarian relief agencies and partners in responding to the South Asian earthquake. The main functions of $\mathrm{WHO}$ in such a crisis are to:

- measure ill-health and promptly assess the health needs of populations affected by crises, identifying priority causes of ill-health and death;

- support Member States in coordinating action for health;

- ensure that critical gaps in the health response are rapidly identified and filled;

- revitalize and build the capacity of health systems for preparedness and response.

In addition to its HAC programme, last year WHO set up the Strategic Health Operations Centre at its Geneva headquarters, known as the SHOC room, which is a computerized, Internet-based, coordinating centre which operates 24 hours a day in disasters to coordinate emergency health relief.

\section{SOUTH ASIAN EARTHQUAKE}

On 8 October 2005, an earthquake struck northwestern Pakistan and the Kashmir region, registering 7.6 on the Richter scale. Nearly half the population lost their homes, leaving 2.5 million people without shelter. Overall, 3 to 3.5 million people were directly affected by this earthquake. This emergency was designated a complex emergency, meaning multi-agency and multi-sector resources are needed to tackle it.

In this humanitarian crisis, WHO registered reports of high mortality, hypothermia, asphyxia, dust inhalation, exposure to extreme winter conditions which had already set in, burns, electroshocks, acute respiratory infections, and a major impact of tuberculosis through damaged water supplies. Indirectly, there was major damage to health facilities, which meant that basic health care services could not operate, as well as massive damage to lifelines, water, sewage, electricity and energy lines, including the destruction of roads, telecommunications, and even the airport.

The disaster was labeled the "Winter Race" operation by those working on it. WHO focused on limiting the health impact and death toll through emergency services and health professional action. WHO's partners also played a vital role in supplying such emergency equipment as winterized tents, galvanized iron and plastic sheeting, and heating for families living in tents. Schools and field hospitals provided basic shelter and basic supplies. A few statistics will present a picture of 
the dimensions of the disaster: there were 25,000 cases of tuberculosis reported in the early days and 5,000 cases of diarrhoeal disease resulting from contaminated water and the lack of sanitation. After medical evacuation, WHO moved in immediately in the aftermath of the disaster.

\section{PARTNERSHIPS}

Partnerships are crucial to how WHO works in a humanitarian crisis. Help is needed with logistics, equipment and supplies, transport, and human resources among other things. Local support at the ground level, including knowledge of the local area, culture and languages, is absolutely vital. WHO cannot operate effectively without this assistance.

In carrying out disaster and emergency relief, WHO always works in collaboration with other UN agencies, such as the United Nations Development Programme (UNDP), the United Nations Children's Fund (UNICEF), the United Nations High Commissioner for Refugees (UNHCR), the Centre for Human Rights, and many other international relief organizations such as the Red Cross, Médecins sans frontières, and the Oxford Committee for Famine Relief (OXFAM), too many to mention here. What is needed in responding to a humanitarian crisis is concerted, coordinated action, a strategy for how to manage a humanitarian crisis, and above all, as far as WHO is concerned, standard operating procedures on how to tackle the health dimensions of such crises.

During the Pakistan earthquake, or "Winter Race" crisis, WHO worked in close partnership with UNICEF, the United Nations Fund for Population Activities (UNFPA), and the International Organization for Migration (IOM). The World Food Programme (WFP) and the Red Cross, both the International Committee and the International Federation, were also operating in close collaboration with WHO. OXFAM played an important role as well in responding immediately to the disaster. A large number of international and local NGOs worked with WHO on the ground, notably a local NGO in Pakistan called RASTI, the Research and Social Training Institute, which had a great deal of local knowledge and was an immense help in the field. These partners all pledged to support the Ministry of Health in Pakistan and the government as a whole in responding to this disaster.

UNICEF was also prominent in its cooperation with WHO and the Ministry of Health in the polio immunization campaign in Pakistan to donate vaccines, provide staff, and encourage the social mobilization of local and other organizations. On this occasion, there was also an outbreak of measles and the fear of it spreading under the disaster conditions. The Pakistan earthquake disaster was notable for the significant number of donors from the private sector who committed their support, not only with donations but by offering the resources, skills, and facilities that only the private sector could rapidly make available. The Pakistan crisis was also characterized by the number of national governments which aided in WHO's mission: Australia, Canada, Denmark, the European Communities, Italy, Switzerland, the United Kingdom and the USA, to mention a few. 
In the immediate follow-up to this emergency, $\mathrm{WHO}$ and the IOM worked together to identify which agency or organization had the comparative advantage to deliver which services. The IOM took charge of the medical evacuation of injured people affected by the earthquake, donated equipment and supplies, and flew staff straight out. They worked with local NGOs to try to re-establish some kind of emergency health services and delivered mental health care and counseling to large numbers of people suffering from anxiety, fear, and depression in the aftermath. Many had lost immediate family members and witnessed terrible injuries and destruction, in addition to losing their homes. WHO and the UNAIDS Programme also played a vital role, as there was concern about the spread of HIV/AIDS in the crisis area. They worked to ensure safe blood transfusions, set up clinics on the spot and were joined by the Aga Khan Foundation to establish appropriate health services.

\section{CONCLUSION}

In the particular case of the Pakistan earthquake disaster of October 2005, as in many other humanitarian crises, WHO was named as the lead agency because of the major health impact of the disaster. WHO first assessed the dimensions of the health impact, identified the health needs and priority causes of ill-health and mortality and took action to prevent further morbidity and mortality. In all cases, WHO works with the government or national authorities of its 193 member states, as determined by its 1947 Constitution.

Partnerships with key local and international organizations and relief agencies are absolutely vital in responding to disasters. The WHO Constitution recognizes that health, peace and security are "dependent on the fullest co-operation of individuals and States." ${ }^{2}$ That interdependence is at the heart of a good relationship. Partnerships were seen as a key element in the response to the Pakistan emergency, as in many other man-made or natural disasters. UN agencies, governments, international and local NGOs, specialist disaster relief organizations, and private enterprise all worked together in a common effort. Each partner had something specific to offer, some comparative advantage in what they could best deliver.

Efforts to rebuild and rehabilitate post-disaster communities and countries continue, with $\mathrm{WHO}$ committed to the long-term development of health infrastructure and national capacity in public health. The Pakistan earthquake crisis was a good model for a study of how partnerships, cooperation and a clear strategy for emergency humanitarian relief pay off. More than ever, the work that goes on will need partnerships. No single UN agency or organization can manage the work of global international development alone. Collaboration, partnerships and common goals are the only way forward.

\footnotetext{
Notes

WHO Constitution WHO Constitution
} 